\title{
UTILIZAÇÃO DE HÍBRIDOS DE AMOREIRA NA PRODUÇÃO DE CASULOS DO BICHO-DA-SEDA (Bombyx mori L.)
}

\section{GERBSON AZEVEDO DE MENDONÇA}

Engenheiro Agrônomo

\author{
Orientador: Prof. Dr. LUÍS CARLOS MARCHINI
}

Dissertação apresentada à Escola Superior de Agricultura "Luiz de Queiroz", da Universidade de São Paulo, para obtenção do título de Mestre em Ciências, Área de concentração: Entomologia.

PIRACICABA

Estado de São Paulo - Brasil

Agosto - 1994 
Ficha catalografica preparada pela Seczo de Livros da Divisato de Eitilioteca e Documentacáo - FCLQ/USF

\footnotetext{
Mendonţa, Gerbson Azevedo de

MS59kx Utilizafáa de hitoridas de amoreira na producáo de casulas do ticho-da-seda (Bombyx mori L.). Firaci caba, 1994 .

$59 \mathrm{p}$.

Diss. (Mestre) - ESALQ

Bibliografia.

1. Eichomda-seda 2. Hibrido de amora - Froututivida de $\$$. Sericituitura Luiz de Queiroz, Firacicata
}

CDD $43 \mathrm{3}=\mathrm{B}$ 


\section{UTILIZAÇÃO DE HIBBIDOS DE AMOREIRA}

NA PRODUÇÃO DE CASULOS DO BICHO-DA-SEDA (Bombyx mori L.)

\section{GERBSON AZEVEDO DE MENDONÇA}

Aprovado em: 27/09/1994

Comissão julgadora:

Prof. Dr. Luís Carlos Marchini

ESALQ/USP

Prof. Dr. José Djair Vendramim ESALQIUSP

Prof. Dr. Roque Takahashi

Aos meus tios,

Jandira e Ábsolon,

OFEREÇO.

Aos meus pais,

MENDONÇA E NEVES

e à minha irmã NANCY,

DEDICO. 


\section{AGRADECIMENTOS}

Ao Professor Dr. Luís Carlos Marchini, pela orientação deste trabalho e amizade durante o curso de pós-graduação;

Ao Centro Estadual de Pesquisa Aplicada em Sericicultura (CEPAS)-IZ, na pessoa do Eng ${ }^{\circ} \mathrm{Agr}^{\circ}$ José Eduardo de Almeida, pela possibilidade da realização do experimento;

Ao CNPq, pela concessão da bolsa durante o curso de pósgraduação;

Ao Professor Dr. José Djair Vendramim, do Departamento de Entomologia da ESALQ/USP, pela colaboração e amizade, fundamentais a este trabalho;

Ao Professor Dr. Evôneo Berti Filho, do Departamento de Entomologia da ESALQ/USP, pela confecção do summary;

Aos Professores Dr. Celso Boin e Dr. Wilson Mattos do Departamento de Zootecnia da ESALQ/USP, pela utilização do Laboratório de Bromatologia;

Aos alunos de pós-graduação do Departamento de Zootecnia da ESALQ/USP, Jozivaldo G.P. Moraes, João Ricardo A. Pereira e Paulo Rossi Jr. e ao técnico Carlos César Alves, pela indispensável colaboração nas análises químicas; 
Aos funcionários do CEPAS-IZ, Lourdes, Marli, Neuza, Maria Luiza, Zilton e Clarindo, pela ajuda valiosa na condução dos experimentos;

Aos amigos do Departamento de Entomologia da ESALQIUSP, professores, funcionários e aos colegas do curso de pós-graduação, pelos momentos agradáveis de convivência;

À minha família que sempre me apoiou e

A Deus, pela força interior. 


\section{SUMÁRIO}

Página

LISTA DE TABELAS $\ldots \ldots \ldots \ldots \ldots \ldots \ldots \ldots \ldots \ldots \ldots$ viii





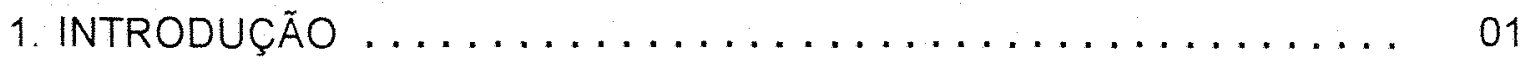

2. REVISÃO DE LITERATURA .................... 03

2.1. Diferenças varietais em amoreira $\ldots \ldots \ldots \ldots$

2.2. Valor nutritivo da amoreira .................. 05

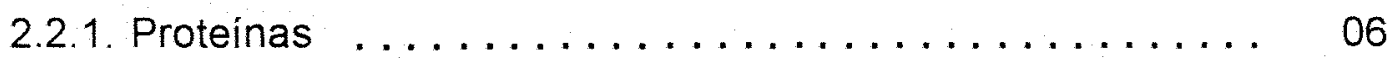

2.2.2. Carboidratos ..................... 09

2.2.3. Relação proteína/carboidrato ... . . . . . . . . . . 12

2.3. Utilização de híbridos de amoreira $\ldots \ldots \ldots \ldots$

3. MATERIAL E MÉTODOS . . . . . . . . . . . . . . . . . . . 17

3.1. Material vegetal utilizado .................... 17

3.2. Análises quimicas das folhas $\ldots \ldots \ldots \ldots 18$

3.2.1. Determinação da proteina bruta $\ldots \ldots \ldots \ldots$

3.2.2. Determinação dos carboidratos solúveis $\ldots . . . \ldots \ldots .19$

3.2.3. Determinação do amido ................... 19

3.2.4. Relação proteína/carboidrato ... . . . . . . . . . . 19

3.3. Obtenção dos insetos ....................... . . 19

3.4. Biologia de $B$. mori em hibridos de amoreira . . . . . . . . . 20

3.5. Produção de casulos . . . . . . . . . . . . . . . . 21

3.6. Delineamento experimental . . . . . . . . . . . . . 22

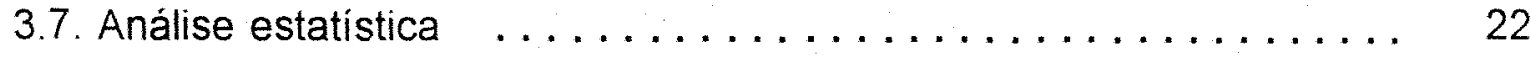




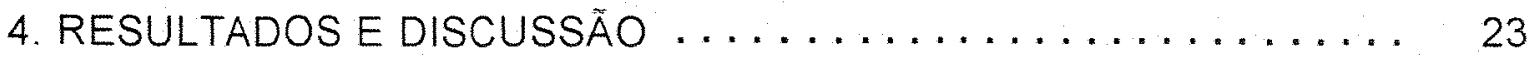

4.1. Análises quimicas das folhas dos genótipos de amoreira ..... 23

4.1.1. Proteina bruta . . . . . . . . . . . . . . 23

4.1.2. Carboidratos solúveis ............... 24

4.1.3. Relação proteína/carboidrato ............. 24

4.1.4. Amido ..................... 25

4.2. Biologia de $B$. mori em híbridos de amoreira . . . . . . 27

4.2.1. Condições ambientais $\ldots \ldots \ldots \ldots \ldots \ldots \ldots \ldots \ldots 27$

4.2.2. Duração dos instares e da fase larval . . . . . . . 27

4.2.3. Porcentagem de encasulamento ............ 32

4.2.4. Peso das lagartas $\ldots \ldots \ldots \ldots \ldots \ldots \ldots \ldots \ldots \ldots$

4.2.5. Peso das pré-pupas . . . . . . . . . . . . . 34

4.2.6. Peso das glândulas sericigenas $\ldots \ldots \ldots \ldots \ldots \ldots . . \ldots$

4.3. Produção de casulos do bicho-da-seda em híbridos de amoreira 37

4.3.1. Peso do casulo $\ldots \ldots \ldots \ldots \ldots \ldots \ldots \ldots \ldots \ldots . \ldots \ldots$

4.3.2. Peso da pupa .................... 38

4.3.3. Peso da casca sérica $\ldots \ldots \ldots \ldots \ldots \ldots \ldots \ldots . . \ldots$

4.3.4. Teor de seda $\ldots \ldots \ldots \ldots \ldots \ldots \ldots \ldots \ldots \ldots \ldots .41$

4.3.5. Comprimento do fio $\ldots \ldots \ldots \ldots \ldots \ldots \ldots \ldots . \ldots 2$

4.3.6. Produção de casulos $\ldots \ldots \ldots \ldots \ldots \ldots \ldots \ldots \ldots 43$

4.3.7. Valor da produção $\ldots \ldots \ldots \ldots \ldots \ldots \ldots \ldots \ldots .45$

5. CONCLUSÕES $\ldots \ldots \ldots \ldots \ldots \ldots \ldots \ldots \ldots \ldots \ldots \ldots \ldots$

REFERENCIAS BIBLIOGRÁFICAS $\ldots \ldots \ldots \ldots \ldots \ldots \ldots \ldots$






\section{LISTA DE TABELAS}

TABELA No

Página

1 Teor de proteina bruta, carboidratos solúveis e relação proteina/carboidrato das folhas de híbridos $e$ de uma variedade de amoreira (Morus spp.) . . . . . . . 25

2 Duração dos ínstares de lagartas do bicho-da-seda (B. mori) alimentado com folhas de hibridos e de uma variedade de amoreira. Gália, SP, 1994. . . . . . . . 29

3 Duração da fase larval e porcentagem de encasulamento de lagartas do bicho-da-seda (B. mori) alimentadas com folhas de hibridos e de uma variedade de amoreira. Gália, SP, 1994

4 Peso das lagartas, das pré-pupas e das glângulas sericígenas do bicho-da-seda (B. mori) alimentadas com folhas de híbridos e de uma variedade de amoreira. Gália, SP, 1994. . . . . . . . . . . . . . . . . 36

5 Peso do casulo, da pupa e da casca sérica do bicho-daseda (B. mori) alimentado com folhas de hibridos e de uma variedade de amoreira. Gália, 1994. ............40

6 Comprimento do fio, teor de seda, produção de casulos e valor da produção do bicho-da-seda (B. mori) alimentado com folhas de hibridos e de uma variedade de amoreira. Gália, SP, 1994 . . . . . . . . . . . . . . . . . . . . . . . . 44 


\title{
UTILIZAÇÄO DE HIBRIDOS DE AMOREIRA NA PRODUÇÃO DE CASULOS DO BICHO-DA-SEDA (Bombyx moriL.)
}

\author{
Autor: Gerbson Azevedo de Mendonça \\ Orientador: Prof. Dr. Luis Carlos Marchini
}

\section{RESUMO}

Foi estudado o efeito de oito híbridos de amoreira (Morus spp.) sobre o desenvolvimento larval e produção de casulos do bicho-da-seda (Bombyx mori L.) (Lepidoptera: Bombycidae). O experimento foi conduzido em sirgaria com temperatura média do ambiente de $25 \pm 3^{\circ} \mathrm{C}$ e umidade relativa do ar de $75 \pm 5 \%$. Foram feitas análises químicas das folhas dos genótipos de amoreira. Os híbridos influenciaram a duração da fase larval, havendo correlação entre este parâmetro e o teor de nutrientes das folhas. Os híbridos de amoreira afetam o peso das lagartas, das pré-pupas e das glândulas sericigenas. A porcentagem de encasulamento foi maior nas lagartas alimentadas com o híbrido $1 Z-15 / 7$. Foi observada correlação negativa entre o teor de carboidratos solúveis das folhas e o peso das pupas. Os híbridos influenciaram o peso da casca sérica, o teor de seda e o comprimento do fio. Os híbridos $\mid Z-57 / 2,1 Z-56 / 4$ e $1 Z-15 / 7$ apresentaram as melhores produções de casulos. O valor da produção total é o parâmetro mais importante na criação do bicho-da-seda e diferiu entre os híbridos testados. 


\title{
UTILIZATION OF HYBRIDS OF MULBERRY \\ IN THE PRODUCTION OF SILKWORM (BOmbyx mori L.) COCOONS
}

\author{
Author: Gerbson Azevedo de Mendonça \\ Adviser: Prof. Dr. Luis Carios Marchini
}

\section{SUMMARY}

This research deals with the effect of eight hybrids of mulberry (Morus spp.) on the larval development and in the production of cocoons of the silkworm (Bombyx mori L.) (Lepidoptera: Bombycidae). The experiment was set in a rearing house (temperature $25 \pm 3^{\circ} \mathrm{C}$; relative humidity $75 \pm 5 \%$ ). The leaves of the mulberry hybrids were chemically analyzed. The hybrids did influence the duration of the larval stage and a correlation was observed between this parameter and the leaf nutrient contents. The mulberry hybrids did influence the weight of the caterpillar, prepupae and of the silk glands. The percentage of silk spinning was best when the caterpillars were fed with the hybrid IZ-15/7. A negative correlation was observed between the contents of leaf soluble carbohydrates and the weight of the pupae. The hybrids did influence cocoon shell weight, silk contents and length of the silk filament. The hybrids $|Z-57 / 2| Z-,56 / 4$ and $\mid Z-15 / 7$ have presented the best production of cocoons. The value of the total production is the most important parameter in silkworm rearing and was different among the hybrids tested. 


\section{INTRODUÇÃO}

Nos últimos dez anos houve uma expansão na sericicultura brasileira, no tocante à área plantada com amoreira e na produção de casulos do bicho-da-seda.

O Brasil ocupa atualmente o quarto lugar como país produtor de casulos e apesar da importância econômica, esta exploração apresenta baixa produção de casulos por área cultivada com amoreira.

Na safra de $1993 / 94$ foram produzidos no Brasil $270 \mathrm{~kg}$ de casulos por hectare plantado com amoreira, enquanto que o Japão em 1989 produziu $417,0 \mathrm{~kg} / \mathrm{ha}$ de amoreira (TODOROKI, 1991).

O alto rendimento alcançado pelo Japão é devido, entre outras técnicas, à utilização de amoreiras hibridas altamente produtivas (HAZAMA, 1968).

A produtividade da sericicultura no Brasil poderá ser alterada com a utilização dos híbridos de amoreira, obtidos a partir de 1965 pelo Eng: Agr? Luiz Paolieri do Instituto de Zootecnia. 
As características agronômicas destas plantas foram estudadas por FONSECA et al. (1985a,b: 1986; 1987a,b,c) e apenas um trabalho utilizou esse material na criação do bicho-da-seda, visando à produção de casulos (FONSECA et al., 1990).

Considerando o potencial produtivo dos hibridos de amoreira e a escassez de pesquisas na área, foi desenvolvido o presente trabalho com o objetivo de avaliar o efeito desses híbridos no desenvolvimento larval e na produção de casulos do bicho-da-seda Bombyx mori, L. 


\section{REVISÃO DE LITERATURA}

\subsection{Diferenças varietais em amoreira}

Os primeiros ensaios de competição de amoreira no Brasil, utilizavam principalmente as variedades Calabresa, Fernão Dias, Lopes Lins, Paduana, Moretiana e Catânia Paulista (RÚBIA, 1964; RÚBIA \& ABRAMIDES, 1965; RÚBIA et al., 1966a). E de acordo com RÚBIA et al. (1966b), PAOLIERI \& FROTA (1970) e FONSECA et al: (1976), houve diferença nas produções de folhas e de casulos do bicho-da-seda (Bombyx mori L.) entre as variedades. Estas variedades praticamente não são mais utilizadas pelos sericicultores brasileiros e poucos são os trabalhos mais recentes de competição de variedades de amoreira.

TAKAHASHI et al. (1987) desenvolveram trabalho com cinco variedades de amoreira (Fernão Dias, Miura, Yamada, Calabresa e Formosa) em seis ensaios sequenciais entre 1982-84, e verificaram diferenças no peso dos casulos para 'Formosa' e 'Calabresa' em relação às demais, apresentando, todavia, valores semelhantes para teor de seda. 
Os trabalhos desenvolvidos no Brasil com variedades de amoreira se concentraram na avaliação da produção de casulos, com poucas informações sobre quantidade e qualidade das folhas. SCARPELLI et al. (1969) determinaram o teor de nitrogênio de oito variedades de amoreira utilizadas na época no Estado de São Paulo. Foram encontradas diferenças entre as variedades e entre a posição da folha no ramo.

Estudos sobre a composição bioquímica e qualidade das folhas indicam que as substâncias nutritivas diferem quantitativamente entre as variedades de amoreira. Ensaios de alimentação provaram que variedades de amoreira têm significativa influência sobre o crescimento e desenvolvimento do bicho-da-seda e na produção de casulos (DAS \& SIKDAR, 1970; TAYADE \& JAWALE, 1984; THANGAMANI \& VIVEKANANDAN, 1984; PERIASMY \& RADHAKRISHNAN, 1985)

A quantidade e qualidade das folhas produzidas pelas variedades de amoreira S54, K2, MR2, Roso e Koosen, foram estudadas no Estado indiano de Tamil-Nadu por PILLAI \& JOLLY (1985), que observaram diferenças no período larval, no peso de lagartas e de casulos do bicho-da-seda.

Além destes parâmetros, as variedades de amoreira influenciam o consumo foliar (AJAY-KOUL, 1986), havendo também interações com as estaçōes do ano (DAS \& VIJAYARAGHAVAN, 1990).

Outras diferenças varietais foram examinadas por MACHII \& KATAGIRI (1991), dando ênfase aos teores de nitrogênio e aminoácidos e a eficiência de produção de casulos, que diferiram entre as variedades e estações do ano. 
QADER et al. (1992) verificaram a influência de variedades de amoreira no desenvolvimento larval e produção de casulos de B. mori. Observaram que o peso de lagartas, peso do casulo e da casca sérica e o comprimento do fio foram grandemente influenciados pelo valor nutritivo das variedades estudadas, concluindo que as diferenças varietais da amoreira refletem a qualidade da folha nos parâmetros biológicos do bicho-da-seda.

\subsection{Valor nutritivo da amoreira}

A composição química da folha de amoreira varia em função de elementos da planta tais como: posição da folha no ramo, estágio de desenvolvimento e variedade, que por sua vez são influenciados por fatores do ambiente, determinando assim, a qualidade da folha (IDE, 1969).

O valor nutritivo da folha exerce uma considerável influência sobre o crescimento do bicho-da-seda e tem sido um dos principais objetivos do melhoramento da amoreira (HIRANO, 1982).

O desenvolvimento larval e as características do casulo como o peso da casca sérica, o teor de seda e o comprimento do fio são influenciados pela quantidade de nutrientes da folha de amoreira, destacando-se as proteinas e açúcares solúveis (PERIASAMY \& RADHAKRISHNAN, 1985). 
Além da quantidade, a qualidade da folha desempenha um efeito direto na vitalidade do bicho-da-seda e na produção de casulos (PANGCHUAN \& DA-CHUANG, 1988).

Folhas de amoreira com maiores quantidades de nutrientes proporcionam maior desenvolvimento das glândulas sericigenas e maior peso de casulos (TAKAHASHI et al., 1990).

\subsubsection{Proteinas}

Nos produtos destinados à alimentação animal, é muito importante a fração denominada proteina bruta, que normalmente corresponde ao valor do nitrogênio total multiplicado por 6,25 e expresso em porcentagem do peso seco. Este valor do nitrogênio total engloba outros nitrogênios que não são exclusivamente os das proteínas, como o nitrogênio inorgânico, calculando-se em 75 a $85 \%$ da proteina bruta a porção que corresponde às proteinas verdadeiras (CORREA, 1983).

Os efeitos de niveis de proteina na dieta sobre o crescimento, metabolismo do nitrogênio e produção de seda foram amplamente estudados, principalmente no Japão (ITO \& ARAI, 1965; ARAI \& ITO, 1967; HORIE et al., 1970; HORIE \& WATANABE, 1983; HAMANO \& OKANO, 1989). Os autores concluíram que a elevação da quantidade de proteínas na dieta até um nivel ótimo, 
resulta na aceleração do crescimento da lagarta e no aumento da produção de seda.

O bicho-da-seda utiliza eficientemente o nitrogênio da folha de amoreira. A lagarta digere e absorve cerca de $60 \%$ do total de nitrogênio ingerido e cerca de $65 \%$ do nitrogênio digerido é utilizado para as sínteses protéicas da lagarta no $5^{\circ}$ instar, sendo que o nível ótimo de proteinas requerido do alimento varia de 22 a $25 \%$ (HORIE, 1978).

Entretanto, HAMANO \& OKANO (1989) determinaram uma faixa ótima entre 20 e $30 \%$ de proteínas na dieta para o bicho-da-seda, sendo que 0 alimento com niveis maiores que 30 e menores que $20 \%$ de conteúdo protéico resultaram em menor desenvolvimento larval. Fato este confirmado por SAVOPOULOU-SOULTANI et al. (1994), que observaram o desenvolvimento de Lobesia botrana (Lep.: Tortricidae) prolongado em dietas com níveis muito altos ou muito baixos de proteinas, sendo mais curto em concentrações protéicas intermediárias. Foi concluido que dentro de determinados limites, o teor de proteinas não influencia o desenvolvimento larval. A influência acontece quando os niveis de proteínas são extremos. SUDO et al. (1981), verificaram alta correlação entre o teor de nitrogênio nas folhas e o peso das lagartas, peso de casulos e quantidade de seda produzida.

Assim, THANGAMANI \& VIVEKANANDAN (1984) verificaram maiores viabilidade larval, teor de seda e comprimento do fio quando as lagartas foram alimentadas com folhas com maior conteúdo de proteínas. 
NAGATA \& KOBAYASHI (1990) divulgaram que o nivel de proteina da hemolinfa varia em função do nível existente no alimento, sendo que maiores quantidades de proteína proporcionaram maior peso e comprimento larval.

O teor de proteínas da folha de amoreira situa-se quase sempre no intervalo entre 20 e $30 \%$. HIRANO (1982) encontrou entre dezessete variedades japonesas de 21,6 a $32,7 \%$ de proteina. THANGAMANI \& VIVEKANANDAN (1984) determinaram 21,4 a $29,4 \%$ de proteinas em variedades cultivadas na Índia. No Brasil, esses valores situam-se entre 24,8 e $28,8 \%$ de acordo com a adubação (TAKAHASHI \& KRONKA, 1989) e entre 24,6 e $30,5 \%$ na primavera; 24,3 e $29,2 \%$ no verão e de 21,4 e $30,6 \%$ no outono, para híbridos de amoreira (FONSECA et al., 1993).

Não só a quantidade de proteínas da folha de amoreira é importante, mas também a sua qualidade, uma vez que o valor de qualquer proteina ingerida por um inseto depende do conteúdo de aminoácidos da mesma e da habilidade do inseto de digeri-la (CHAPMAN, 1982). Além de que, o nitrogênio pode não estar totalmente disponivel para o inseto ou a proporção entre os aminoácidos pode ser insatisfatória (MCNEILL \& SOUTHWOOD, 1978).

O que é limitante para o crescimento e desenvolvimento larval é a quantidade de nitrogênio disponivel. PARRA \& CARVALHO (1984) observaram que não houve correlação entre o desenvolvimento de Spodoptera frugiperda e a proteína total existente em variedades de feijão utilizadas na dieta artificial para este inseto. As lagartas se desenvolveram melhor naquela dieta em que supostamente o nitrogênio se encontrava mais disponivel. 


\subsubsection{Carboidratos}

Os carboidratos são as principais fontes de energia para os insetos, sendo que os mais utilizados pelo bicho-da-seda são as hexoses, dissacarideos e trissacarídeos (DADD, 1985).

ITO (1960), observando a sobrevivência de lagartas com relação a tipos de carboidratos, verificou que sacarose, frutose e rafinose apresentaram altos valores nutritivos, enquanto que lagartas alimentadas com glicosideos e amido, tiveram a taxa de sobrevivência diminuida, sugerindo que o inseto não metaboliza estes carboidratos.

A quantidade de carboidratos ingerida pela lagarta do bicho-daseda varia de 3 a 4 mmoles, sendo que $70 \%$ destes são absorvidos (HORIE, 1978).

Entretanto, a utilização de carboidratos depende da atividade das enzimas digestivas. Em B. mori as enzimas que digerem a sacarose apresentam quantidades elevadas dentro das glicosidases, uma vez que as folhas de amoreira apresentam alto teor daquele carboidrato (HORIE \& WATANABE, 1980). Os carboidratos solúveis representam de 8,6 a $15,5 \%$ da folha de amoreira, de acordo com a variedade (THANGAMANI \& VIVEKANANDAN, 1984).

Os carboidratos têm valores nutritivos para uma espécie de inseto dependendo de três fatores principais: as propriedades fagoestimulantes; os monossacarídeos e moléculas correlatas que podem ser metabolizadas para a produção de energia; e o complemento de enzimas digestivas utilizadas para 
reduzir carboidratos complexos em seus monômeros constituintes (DADD, 1985).

Existe na literatura uma certa discordância quanto ao conteúdo de amido em folhas de amoreira e a utilização deste por lagartas de $B$. mori.

PANG-CHUAN \& DA-CHUANG (1988) observaram o conteúdo de $0,7 \%$ de amido em folhas de amoreira colhidas pela manhã, alcançando um máximo de $2,0 \%$ à tarde, após o período de atividade fotossintética. Todavia, QADER (1991) verificou que o conteúdo de amido varia de 9,17 a $12,09 \%$ em folhas de variedades de amoreira.

Como a folha de amoreira não se constitui órgão de reserva de carboidratos, o valor elevado para amido é de certa forma controvertido, já que YAMASHITA (1983) registrou acúmulo de amido apenas nos ramos de amoreira e principalmente no outono, quando as plantas se apresentavam mais velhas.

YAMASHITA (1986), observando a translocação de carboidratos em amoreira, salientou que a quantidade de amido nesta planta durante o período vegetativo (no qual é utilizada para alimentação do bicho-da-seda) é muito reduzida, já que é convertido em sacarose para suprir o consumo de energia durante o crescimento dos ramos e das raizes.

O fato de que os ramos de amoreira são cortados pela manhã e armazenados para a alimentação diária do bicho-da-seda pode contribuir para uma redução ainda maior no conteúdo de amido da planta. 
Existe uma conversão acelerada de amido para açúcares numa planta com deficiência de água, sugerindo que a taxa respiratória aumenta por causa do déficit hídrico (VAADIA et al., 1961).

Outro fator que pode ter influenciado os valores divergentes para amido em folhas de amoreira foi o método de determinação utilizado, já que muitas vezes, carboidratos estruturais (celulose e hemicelulose) podem ser confundidos com amido (JACQUES, 1973).

Quanto à utilização deste carboidrato, TANAKA \& KUSANO (1980) ressaltaram que a amilase do tubo digestivo do bicho-da-seda participa da digestão do amido da folha de amoreira, o que discorda de HORIE \& WATANABE (1980) que salientaram que em raças comerciais de $B$. mori, devido a fatores genéticos faltam amilases ativas, sugerindo que essas enzimas podem não ser efetivas na digestão.

DADD (1985), salientou que lagartas filófagas que requerem carboidratos na alimentação não utilizam o amido, e quando utilizam, o faz muito pobremente.

De acordo com SHAW (1973), cerca de $20 \%$ do amido é composto por amilose, que é um carboidrato solúvel e este componente é o mais provável de ser utilizado nutricionalmente pelo inseto. 


\subsubsection{Relação proteina/carboidrato}

A composição nutricional de um alimento para insetos inclui quantidades absoluta e relativa de proteínas e aminoácidos, lipídios, minerais, água e carboidratos. Para crescimento, desenvolvimento e reprodução ótimos, além da quantidade, esses nutrientes precisam obedecer certas proporções entre si (SLANSKY \& SCRIBER, 1985).

Proteinas ou aminoácidos são essenciais à dieta dos insetos em desenvolvimento e são exigidos em altas concentrações para um crescimento perfeito. Os nutrientes devem estar adequadamente balanceados entre si, especialmente a relação proteína/carboidrato (PARRA, 1991).

Para B. mori, a proporção de nutrientes é muito importante para um ótimo crescimento de lagartas e especialmente para o desenvolvimento das glândulas sericigenas e a produção de seda. A proporção entre proteinas e carboidratos influencia não somente o desenvolvimento larval como também a produção e qualidade de casulos (KASTURI BAI, 1984).

São utilizadas quantidades idênticas de proteínas e carboidratos em dietas artificiais para o bicho-da-seda (SING, 1977).

A alimentação de lagartas de $B$. mori com folhas velhas de amoreira com alta quantidade de carboidratos e baixa quantidade de proteínas, promove um crescimento lento das lagartas e menor peso de casulos (LI \& SANG, 1984). Neste caso, além de análises químicas, as propriedades físicas podem ser um critério de avaliação da qualidade da folha. 
O requerimento em proteinas e energia para o bicho-da-seda varia com o desenvolvimento larval, já que são necessárias quantidades diferentes de proteina e energia para quantidades idênticas em ganho de peso (MURARI, 1993).

THANGAMANI \& VIVEKANANDAN (1984) verificaram que as variedades de amoreira com maiores quantidades de proteínas e carboidratos solúveis não foram necessariamente as que proporcionaram maiores desenvolvimento de lagartas e produção de casulos. Foi verificado que o maior peso da casca sérica foi obtido daquela variedade com o teor de proteína mais elevado, enquanto que variedades com valores altos de carboidratos solúveis produziram lagartas mais pesadas. Segundo estes autores, a relação entre proteínas e carboidratos varia entre 1,44 e 3,18, não havendo correlação entre as proporções destes nutrientes e os parâmetros biológicos do bicho-da-seda.

\subsection{Utilização de amoreiras hibridas}

O plantio de amoreiras híbridas é adotado na maioria dos paises que exploram a sericicultura, aproveitando as vantagens oferecidas pela heterose (FONSECA et al, 1985a).

De acordo com FONSECA et al. (1976), os amoreirais do Estado de São Paulo, eram em 1969, formados principalmente por variedades 
comuns e pouco produtivas, onde $91 \%$ da área era plantada com 'Calabresa'. Levantamento realizado por TINOCO et al. (1991), confirma a utilização de variedades comuns, como a Miura, Calabresa e Korin com 44,6; 18,1 e $9,8 \%$ da área plantada com amoreira, respectivamente.

Dada a importância da utilização de variedades melhoradas, GUPTA et al. (1986) evidenciaram a utilização da variedade S-799 que produz $78 \%$ mais folhas que a variedade Kajli, tradicionalmente cultivada em Bengala Ocidental, na Índia.

Embora existam variedades mais produtivas que outras, 0 aumento da produtividade da sericicultura brasileira passa, não obstante, por trabalhos de melhoramento da amoreira através de hibridização, elegendo as variedades mais produtivas e adequadas à criação do bicho-da-seda.

Sendo assim, em 1965 o pesquisador Luiz Paolieri da Seção de Sericicultura do Instituto de Zootecnia, deu inicio a um plano de melhoramento de amoreiras, que teve o objetivo de produzir plantas vigorosas, altamente produtivas e nutricionalmente adequadas ao bicho-da-seda (FONSECA et al., 1985b).

Por meio desse plano de melhoramento, foram obtidas, até 1971, um total de 619 plantas híbridas, que foram selecionadas, sendo as 28 mais produtivas colocadas em ensaios de competição (FONSECA et al., 1987b).

Sobre produtividade de plantas híbridas de amoreira no Brasil, o primeiro trabalho foi publicado por FONSECA \& VENCOVSKY (1981), que 
observaram parâmetros de variação fenotípica e genética da produção de folhas e de outras características importantes para sericicultura. Os autores concluíram que existe grande diversidade genotípica no material estudado, do qual se destacaram em produção, os híbridos IZ-13/6 e IZ-19/13*.

Além das plantas resultantes de cruzamentos controlados (híbrido artificial), existem ainda os hibridos naturais, resultantes de cruzamentos aleatórios em campo aberto, entre as variedades que existiam no Posto Experimental de Limeira (SP), do Instituto de Zootecnia.

A partir de 300 plantas híbridas obtidas destes cruzamentos naturais, foram selecionadas as 64 mais produtivas e destas, escolhidas $15 \mathrm{com}$ melhores características do ponto de vista sericícola (FONSECA et al., 1985a).

Para comparação destes, FONSECA et al. (1986) realizaram estudos de competição entre nove híbridos naturais, dois artificiais e a variedade Calabresa, destacando-se os híbridos 1 Z-19/13 e IZ-40 em número de galhos e peso de folhas.

Estudos posteriores foram realizados comparando-se outros híbridos com alguns já testados, destacando-se o IZ-19/13 e IZ-3/2 (FONSECA et al., 1987a). Além disso, quando comparados entre si, 19 híbridos naturais e artificiais e a variedade Calabresa, em observações sobre peso verde de folhas e galhos e número de galhos, os melhores foram os híbridos $I Z-19 / 13$ e $\mid Z-56 / 4$ (FONSECA, 1987b).

* $I Z=$ Instituto de Zootecnia e número do cruzamento. 
Em seguida, FONSECA et al. (1987c) compararam 4 variedades, 9 híbridos naturais e 19 hibridos artificiais de amoreira e observaram que IZ-56/4, IZ-13/6 e IZ-40 apresentaram maiores produções de folhas.

ALMEIDA et al. (1991) verificaram que o hibrido IZ-19/13 além de ser mais produtivo, também apresenta maior estabilidade de produção entre as estações do ano (primavera e verão), contrastando com o IZ-64 que apresentou grande variação na produção.

Em FONSECA et al. (1987b), é evidenciada a necessidade de utilização destes híbridos em ensaios com o bicho-da-seda, visando à produção de casulos.

Embora os híbridos tenham sido largamente estudados em ensaios de competição no campo, existe apenas um trabalho envolvendo-os na alimentação do bicho-da-seda (FONSECA et al., 1990). Estes autores alimentaram lagartas do bicho-da-seda com a variedade Calabresa nos dois primeiros ínstares. A partir do terceiro, as lagartas foram alimentadas com folhas das variedades Calabresa, Catânia 1, dos híbridos artificiais IZ-3/2, IZ-13/6, IZ-15/7, IZ-19/13, IZ$56 / 4, \mid Z-57 / 2$ e híbridos naturais $\mid Z-30$ e $\mid Z-40$. Houve diferenças para peso de casulos, entretanto, não foram observadas diferenças para teor de seda. 


\section{MATERIAL E MÉTODOS}

O trabalho foi desenvolvido no Centro Estadual de Pesquisa Aplicada em Sericicultura (CEPAS), do Instituto de Zootecnia em Gália - SP. durante o mês de março de 1994, utilizando-se lagartas do bicho-da-seda (Bombyx mori L., 1758) alimentadas com híbridos de amoreira (Morus spp.) e a variedade Korin.

\subsection{Material vegetal utilizado}

O estudo constou da criação de lagartas do bicho-da-seda em folhas de oito híbridos de amoreira (IZ-3/2, IZ-13/6, IZ-15/7, IZ-19/13, IZ-56/4, IZ$57 / 2$, IZ-40 e IZ-64), escolhidos devido ao seu potencial produtivo de folhas e da variedade Korin, como tratamento padrão por ser muito utilizada pelos sericicultores do Estado de São Paulo. Os genótipos foram obtidos do plantio localizado no CEPAS, em Gália, SP.

As plantas de amoreira utilizadas tinham idade média de oito anos, com 65 dias da última poda, estando em solo Podzolizado Lins-Marilia, var. 
Marilia, em espaçamento de $2,0 \times 0,5 \mathrm{~m}$. Vinte dias após a última poda, as amoreiras receberam adubação de manutenção de 30 gramas por planta de NPK (sulfato de amônia, superfosfato simples e cloreto de potássio) na formulação 20-515.

\subsection{Análises químicas das folhas de amoreira}

Nos $2^{\circ}, 4^{\circ}$ e $6^{\circ}$ dias do quinto ínstar, foi retirado um ramo de amoreira dentre os que serviriam de alimento para as lagartas, sendo as folhas colhidas, retirados os peciolos e secas em estufa a $65^{\circ} \mathrm{C}$ por 72 horas. As análises químicas foram realizadas no Laboratório de Bromatologia do Departamento de Zootecnia da ESALQ/USP. Foram feitas correlações entre os parâmetros biológicos do bicho-da-seda e o teor de nutrientes das folhas dos genótipos de amoreira testados.

\subsubsection{Determinação da proteína bruta}

Através do método de Kjeldahl foi determinada a porcentagem do nitrogênio total com base no peso seco da amostra. $O$ valor encontrado foi multiplicado por 6,25 para obtenção do valor da proteína bruta. 


\subsubsection{Determinação dos carboidratos solúveis}

O método utilizado na determinação dos carboidratos solúveis das folhas dos genótipos de amoreira foi citado por JOHNSON et al. (1966).

\subsubsection{Determinação do amido}

A determinação do amido foi feita através do método citado por MACRAE \& ARMSTRONG (1968), modificado por POORE et al. (1989).

\subsubsection{Relação proteína/carboidrato}

A relação proteina/carboidrato foi determinada pela divisão do teor de proteína bruta pelo teor de carboidratos não-estruturais totais (carboidratos solúveis e amido) das folhas dos genótipos de amoreira testados.

\subsection{Obtenção dos insetos}

As lagartas de $B$. mori foram obtidas a partir de ovos de hibrido comercial da Fiação de Seda BRATAC SIA, de Bastos, SP. 
Os ovos foram separados em nove grupos de $0,5 \mathrm{~g}$ em placas de Petri e mantidos em sala com ambiente controlado (Temperatura: $26 \pm 1^{\circ} \mathrm{C}$; UR: $80 \pm 5 \%$ e fotofase Oh) até o $11 \%$ dia da incubação, quando foram fornecidas 12 horas de luz para uniformidade da eclosão no dia seguinte.

\subsection{Biologia de B. mori em híbridos de amoreira}

Após a eclosão, as lagartas foram transferidas para caixinhas de madeira $(30 \times 20 \times 2 \mathrm{~cm})$, em seguida levadas para sirgaria experimental com temperatura de $27 \pm 1^{\circ} \mathrm{C}$; UR: $75 \pm 5 \%$ e fotofase de 12 horas, ficando até o final do $2^{\circ}$ instar, recebendo alimento cinco vezes ao dia com folhas tenras e picadas do terço apical dos genótipos de amoreira estudados.

Em todas as ecdises foi polvilhada cal hidratada sobre as lagartas para prevenção de doenças.

Por ocasião da segunda ecdise, 58 lagartas foram colocadas em caixas de criação de madeira, com dimensões de $80 \times 70 \times 3 \mathrm{~cm}$, forradas com papel-jornal e transferidas para a sirgaria definitiva.

As caixas de criação (repetição) ficaram sobre estrados de madeira com $70 \mathrm{~cm}$ de altura no interior da sirgaria de alvenaria, com $420 \mathrm{~m}^{2}$, desinfectada com formol à concentração de $3 \%$, cinco dias antes. 
A temperatura e a umidade relativa do ar foram obtidas através de leituras diárias em psicrômetro.

A alimentação dos terceiro e quarto instares constou dos dois terços superiores dos ramos das amoreiras e no quinto instar foram fornecidos ramos inteiros às $7,10,13,16$ e 19:00 horas.

Para determinação de cada ínstar, foi observada a imobilidade das lagartas (sono), que ocorre distintamente a cada ecdise. Para determinação do peso no máximo desenvolvimento larval, observou-se o surgimento das primeiras pré-pupas, ocasião na qual as lagartas foram pesadas.

$\mathrm{Na}$ fase de pré-pupa foi oferecido às lagartas de cada repetição 1,0 metro de bosque plástico para encasulamento.

Nesta fase, três insetos de cada repetição foram pesados, mortos por congelamento e dissecados para obtenção dos pesos das glândulas sericigenas. A porcentagem de encasulamento foi determinada pela relação entre o número de casulos produzidos e o número de lagartas no início do experimento, descontadas as três pré-pupas utilizadas para obtenção do peso das glândulas sericigenas.

\subsection{Produção de casulos}

Seis dias após o encasulamento, a produção foi pesada e retirada uma amostra de trinta casulos de cada repetição para determinação do 
peso destes, das pupas e da casca sérica. As pesagens foram feitas em balança de precisão até centigrama.

O teor liquido de seda foi obtido pela razão entre o peso da casca sérica e o peso do casulo, diminuídos $24 \%$ de resíduos e dado em porcentagem.

O valor da produção total dos tratamentos foi obtido através da tabela de preços da Indústria de Seda BRATAC SIA.

Para determinação do comprimento do fio de seda, foram utilizadas três amostras de dez casulos de cada tratamento, desenrolados por meio de uma aspa com conta-giros.

\subsection{Delineamento experimental}

Foi utilizado o delineamento experimental inteiramente casualizado com nove tratamentos, oito repetições e 58 lagartas por repetição.

\subsection{Análise estatística}

Os resultados foram analisados pelo teste $F$ e as médias comparadas pelo teste de Tukey, ao nivel de $5 \%$ de probabilidade. 


\section{RESULTADOS E DISCUSSÃO}

\subsection{Análises químicas}

\subsubsection{Proteina bruta}

No resultado das análises do nitrogênio total para obtenção do teor de proteina bruta, pode-se observar diferenças numéricas significantes entre os genótipos (Tabela 1). Como a proteína das folhas de amoreira é um dos principais nutrientes constituintes, estes resultados supõem que 0 alimento com maior teor de proteina seja mais adequado ao desenvolvimento do bicho-da-seda.

Os hibridos $1 Z-13 / 6, \quad Z-56 / 4, I Z-15 / 7$ e IZ-40 apresentam 0 conteúdo de proteina das folhas superior a $25 \%$. FONSECA et al (1993) em análises químicas destes materiais observaram quantidades que variaram de 24,3 a $29,2 \%$ entre os híbridos no verão, mesma época do ano da instalação deste trabalho. 
TAKAHASHI \& KRONKA (1989) verificaram o teor de proteina da variedade de amoreira Miura entre 24,8 a $28,8 \%$ de acordo com a adubação do solo.

\subsubsection{Carboidratos solúveis}

Entre os tratamentos, foi verificada variação no teor de carboidratos solúveis das folhas (Tabela 1).

O teor de carboidratos solúveis determinado, concorda com os dados de THANGAMANI \& VIVEKANANDAN (1984), que observaram de 8,64 a $15,58 \%$ e com QADER (1991) que registrou o intervalo de 10,47 a $14,73 \%$ de carboidratos solúveis nas folhas de variedades de amoreira. Os autores atribuem essas variações a possiveis diferenças varietais na capacidade fotossintética das plantas.

\subsubsection{Relação proteina/carboidrato}

A relação proteina/carboidrato representa num só valor, a quantidade relativa entre si, destes compostos. Os valores diferiram numericamente desde 1,48 nas folhas do híbrido IZ-19/13 até 2,39 em 'IZ-13/6' e 'IZ-15/7' (Tabela 1). Estes valores estão coerentes com aqueles registrados por THANGAMANI \& VIVEKANANDAN (1984) de 1,72 a 3,18 e com QADER (1991) que determinou a relação proteina/carboidrato entre 1,45 e 2,04 . 
Tabela 1. Teor de proteina bruta, carboidratos solúveis e relação proteina/carboidrato das folhas de hibridos e de uma variedade de amoreira (Morus spp.).

\begin{tabular}{|c|c|c|c|}
\hline Híbridos & $\begin{array}{c}\text { Proteína } \\
\text { bruta } \\
(\%)\end{array}$ & $\begin{array}{c}\text { Carboidratos } \\
\text { solúveis } \\
(\%)\end{array}$ & $\begin{array}{c}\text { Relação } \\
\text { proteinal } \\
\text { carboidratos }\end{array}$ \\
\hline $\mid Z-3 / 2$ & 22,82 & 15,03 & 1,51 \\
\hline $\mid Z-13 / 6$ & 25,64 & 10,70 & 2,39 \\
\hline $\mid Z-15 / 7$ & 26,29 & 10,98 & 2,39 \\
\hline $1 Z-19 / 13$ & 22,73 & 15,26 & 1,48 \\
\hline IZ-56/4 & 25,91 & 11,26 & 2,30 \\
\hline $\mid Z-57 / 2$ & 22,07 & 9,87 & 2,23 \\
\hline $1 Z-40$ & 26,60 & 11,20 & 2,37 \\
\hline IZ-64 & 21,98 & 13,37 & 1,64 \\
\hline Var. Korin & 22,39 & 10,12 & 2,21 \\
\hline
\end{tabular}

\subsubsection{Amido}

Nas análises de amido das folhas dos hibridos de amoreira estudados e da variedade Korin, não foram detectadas leituras no espectrofotômetro, não diferindo amostra padrão, que não contém amido. 
PANG-CHUAN \& DA-CHUANG (1988), registraram $0,7 \%$ de amido nas folhas de amoreira colhidas pela manhã e 2,0\% nas folhas colhidas das plantas à tarde. Estes resultados mostram que há um acúmulo durante o dia, via fotossintese, e uma redução da quantidade de amido à noite.

Isto suporta os resultados encontrados neste trabalho, já que as folhas utilizadas nas análises foram retiradas dos ramos de amoreira, que serviriam como alimento do bicho-da-seda. Na prática sericicola, como também neste trabalho, os ramos de amoreira são colhidos pela manhã e armazenados em depósito de folhas para a alimentação diária das lagartas de B. mori.

Neste caso se existia amido nas folhas dos híbridos e da variedade Korin, foi certamente consumido ou reduzidos em outros carboidratos durante o armazenamento.

QADER (1991), verificou entre 9,17 e $12,09 \%$ de amido nas folhas de variedades de amoreira. Os valores elevados que discordam da literatura, talvez possam ser explicados por JACQUES (1973), que citou a existência de discordâncias entre métodos de análises de amido em tecidos vegetais. Às vezes carboidratos estruturais como a celulose e hemicelulose podem ser confundidos com amido.

Salienta-se que as folhas da amoreira não são órgãos de reserva da planta, sendo que os carboidratos na forma de amido são acumulados apenas no caule da planta (YAMASHITA, 1983). 


\subsection{Biologia de B. mori em hibridos de amoreira}

\subsubsection{Condições ambientais}

As médias de temperatura e umidade relativa observadas durante a condução do experimento nos três últimos instares foram, respectivamente, $25 \pm 3^{\circ} \mathrm{C}$ e $75 \pm 5 \%$.

\subsubsection{Duração dos ínstares e da fase larval}

Os resultados obtidos para a duração do primeiro ínstar entre os tratamentos não diferiram entre si, embora os hibridos $1 Z-13 / 6,1 Z-15 / 7,1 Z-57 / 2$, IZ-40 e IZ-64 tenham apresentado uma tendência para maior período do instar (Tabela 2).

Para o segundo instar, foram verificadas diferenças estatisticas e a tendência do ' $\mid Z-40$ ' em alongar a duração dos instares foi confirmada, embora não tenha sido para os outros materiais citados. As lagartas alimentadas neste genótipo apresentaram a duração do segundo ínstar semelhante àquela do ' $I Z-3 / 2$ ' e da variedade Korin, diferindo para todos os outros materiais (Tabela 2).

No periodo do terceiro ínstar não foram verificadas diferenças significativas, embora os híbridos $1 Z-15 / 7, \quad I Z-57 / 2, \quad I Z-40$ e $\quad I Z-64$ tenham apresentado uma tendência para duração um pouco maior do instar (Tabela 2). 
O hibrido IZ-56/4 e a variedade Korin proporcionaram menores periodos para o quarto ínstar, cujas médias não diferiram do ' $I Z-40^{\prime}$, diferindo, entretanto, dos outros híbridos. As lagartas alimentadas com as folhas do ' $I Z-40$ ' tiveram a duração do quarto instar que não diferiu estatisticamente dos demais genótipos, funcionando como tratamento intermediário entre aqueles cujas lagartas passaram cinco ou cinco dias e meio no quarto ínstar.

As diferenças foram maiores para duração do quinto ínstar. Neste, as lagartas alimentadas na variedade Korin apresentaram o período mais curto, o qual não diferiu dos resultados observados nos híbridos $\mid Z-56 / 4$ e $\mid Z-15 / 7$, estes por sua vez, não diferiram estatisticamente dos encontrados nos tratamentos do ' $I Z-3 / 2^{\prime}$ e $' I Z-13 / 6^{\prime}$ mas diferiram dos restantes (Tabela 2).

Os tratamentos onde as lagartas passaram mais de oito dias no último instar, além de diferirem dos demais, também apresentaram valores médios diferentes entre si. O híbrido IZ-64 que proporcionou maior duração do instar, foi semelhante ao tratamento ' $\mid Z-40^{\prime}$ e diferiu do ' $Z$ Z-19/13' e 'IZ-57/2'. Estes genótipos, exceto $0^{\prime} \mid Z-40^{\prime}$, apresentaram baixo teor de proteína nas folhas, sugerindo que sua menor concentração no alimento pode afetar o desenvolvimento das lagartas do bicho-da-seda. 
Tabela 2. Duração dos ínstares (dias) de lagartas do bicho-da-seda (B. mori) alimentadas com folhas de híbridos e de uma variedade de amoreira. Gália-SP, 1994.

Instar

Hibridos

1 ?

$2^{\circ}$

3?

4 ?

5 ?

\begin{tabular}{|c|c|c|c|c|c|}
\hline $\mid Z-3 / 2$ & $4,12 a$ & $3,25 a b$ & $4,12 \mathrm{a}$ & $5,50 \quad b$ & $7,37 \mathrm{~b}$ \\
\hline $\mid Z-13 / 6$ & $4,25 a$ & $3,00 \mathrm{a}$ & $4,21 a$ & $5,50 \quad b$ & $7,37 \mathrm{~b}$ \\
\hline $\mid Z-15 / 7$ & $4,25 \mathrm{a}$ & $3,00 \mathrm{a}$ & $4,25 a$ & $5,50 \mathrm{~b}$ & $7,27 a b$ \\
\hline $\mid Z-19 / 13$ & $4,12 a$ & $3,18 \mathrm{a}$ & $4,10 a$ & $5,50 \quad b$ & 8,12 \\
\hline $\mid Z-56 / 4$ & $4,12 a$ & $3,00 \mathrm{a}$ & $4,12 a$ & $5,00 \mathrm{a}$ & $7,12 a b$ \\
\hline $\mid Z-57 / 2$ & $4,25 a$ & $3,00 \mathrm{a}$ & $4,25 a$ & $5,50 \mathrm{~b}$ & 8,12 \\
\hline $1 Z-40$ & $4,25 \mathrm{a}$ & $3,50 \quad b$ & $4,25 a$ & $5,12 a b$ & 8,24 \\
\hline IZ-64 & $4,25 a$ & $3,00 \mathrm{a}$ & $4,25 a$ & $5,50 \quad b$ & 8,62 \\
\hline Var. Korin & $4,12 a$ & $3,25 a b$ & $4,12 a$ & $5,00 \mathrm{a}$ & $6,88 a$ \\
\hline
\end{tabular}

As médias seguidas de mesma letra não diferem entre si, pelo teste de Tukey, ao nivel de $5 \%$ de probabilidade.

Ocorreu uma variação significativa na duração da fase larval de B. mori entre os tratamentos (Tabela 3). Os genótipos Korin e IZ-56/4 se destacaram dos demais com menor tempo para o desenvolvimento larval, enquanto 
- 'IZ-64' e ' IZ-40' apresentaram maiores periodos deste parâmetro. Os demais valores foram intermediários e não diferiram entre si.

A amplitude máxima que se pode observar foi de 2,29 dias, entre $0^{\prime} \mid Z-56 / 4$ ' e 'IZ-64', período de tempo significativamente longo numa criação comercial do bicho-da-seda.

Embora não tenha havido alta correlação com 0 teor de proteinas da folha $(-0,19)$, nota-se de modo geral; que os tratamentos com menores quantidades de proteina apresentaram maior período de desenvolvimento larval. Com exceção de ' $\mid Z-40$ ', os híbridos que proporcionaram mais de 25 dias na fase larval, apresentam menos de $23 \%$ de proteínas, sugerindo que variedades de amoreira com maior teor de proteínas nas folhas podem proporcionar um tempo menor no desenvolvimento das lagartas.

Para carboidratos solúveis o coeficiente de correlação foi mais alto e positivo $(0,27)$, supondo que o aumento no teor destes compostos na folha de amoreira pode ser responsável por um maior período larval. Assim, os genótipos IZ-56/4, Korin e $\mid Z-15 / 7$ apresentaram baixos teores de carboidratos solúveis quando comparados com ' $I Z-644^{\prime},{ }^{\prime} \mid Z-3 / 2^{\prime}$ e ' $I Z-19 / 13^{\prime}$ que contiveram mais carboidratos e fase larval mais longa. 
Tabela 3. Duração da fase larval e percentagem de encasulamento do bicho-daseda (B. mori) alimentado com folhas de híbridos e de uma variedade de amoreira. Gália-SP, 1994.

\begin{tabular}{llc}
\hline Híbridos & $\begin{array}{c}\text { Duração da } \\
\text { fase larval } \\
\text { (dias) }\end{array}$ & Encasulamento \\
\hline $\mathrm{Z}-3 / 2$ & $24,36 \mathrm{~b}$ & $84,08 \mathrm{ab}$ \\
$\mathrm{IZ}-13 / 6$ & $24,33 \mathrm{~b}$ & $81,81 \mathrm{ab}$ \\
$\mathrm{IZ}-15 / 7$ & $24,27 \mathrm{ab}$ & $84,76 \mathrm{a}$ \\
$\mathrm{IZ}-19 / 13$ & $25,03 \mathrm{bc}$ & $79,54 \mathrm{ab}$ \\
$\mathrm{IZ}-56 / 4$ & $23,36 \mathrm{a}$ & $83,40 \mathrm{ab}$ \\
$\mathrm{IZ}-57 / 2$ & 25,22 bc & $83,17 \mathrm{ab}$ \\
$\mathrm{IZ}-40$ & $25,36 \mathrm{c}$ & $77,27 \mathrm{~b}$ \\
$\mathrm{IZ}-64$ & $25,65 \mathrm{c}$ & $79,76 \mathrm{ab}$ \\
Var. Korin & $23,37 \mathrm{a}$ & $82,04 \mathrm{ab}$ \\
\hline
\end{tabular}

As médias seguidas de mesma letra não diferem entre si, pelo teste de Tukey, ao nivel de $5 \%$ de probabilidade.

A hipótese de que mais proteínas e relativamente menos carboidratos das folhas de amoreira podem proporcionar um periodo larval mais curto é suportada pela relacão proteínas/carboidratos que apresentou uma correlação negativa $(-0,30)$ com a duração da fase larval do bicho-da-seda. 
Estes resultados concordam com ITO (1960), que observou o alongamento da fase larval de $B$. mori de acordo com os tipos de carboidratos utilizados pelas lagartas desta espécie.

\subsubsection{Porcentagem de encasulamento}

O termo porcentagem de encasulamento é mais adequado a estudos do bicho-da-seda do que viabilidade larval, já que apenas as lagartas que tecem o casulo têm valor comercial ou biológico.

Verifica-se que, de modo geral, os efeitos dos materiais testados foram pouco pronunciados estatisticamente (Tabela 3), havendo diferença apenas entre o híbrido $I Z-15 / 7$ que foi superior e o ' $I Z-40$ ' que apresentou menor valor para este parâmetro. Os outros híbridos e a variedade Korin não diferiram entre si ou dos hibridos já citados.

Como não houve correlação significativa com as proteínas e carboidratos solúveis das folnas dos genótipos estudados, pode-se atribuir essas diferenças a outros fatores do alimento.

O intervalo de porcentagem de encasulamento observado de $77,27 \%$ no ' $I Z-40^{\prime}$ a $84,76 \%$ no híbrido $I Z-15 / 7$ foi mais reduzido do que 0 determinado por SHARMA et al. (1986) que variou de 60 a $100 \%$ e semelhante àquele $(75,1-83,5 \%)$ observado por SARATCHANDRA et al. (1992) para lagartas alimentadas com variedades indianas de amoreira. 
Embora os resultados não tenham produzido maiores diferenças estatísticas, numa criação comercial do bicho-da-seda esses valores podem causar efeitos acentuados na produção de casulos, já que comumente criam-se centenas de milhares de lagartas.

\subsubsection{Peso das lagartas}

O peso das lagartas no máximo desenvolvimento (Tabela 4) foi influenciado pelos híbridos de amoreira utilizados, com relação à variedade Korin. Este parâmetro não apresentou diferenças entre os híbridos e apenas as lagartas alimentadas com folhas da 'Korin' tiveram resultado que diferiu estatisticamente dos pesos das lagartas alimentadas com os híbridos $1 Z-13 / 6$ e IZ-15/7. Entretanto, quando comparados o peso das lagartas e a duração da fase, os híbridos $\mid Z-15 / 7$ e IZ-56/4 se destacaram dos demais, apresentando os melhores resultados destes parâmetros.

Os hibridos $I Z-19 / 13,|Z-57 / 2| Z-$,40 e IZ-64 que proporcionaram mais de 25 dias para o periodo larval, não apresentaram necessariamente maior peso das lagartas, evidenciando uma menor adequação desse material ao desenvolvimento larval de $B$. mori.

A correlação entre o peso das lagartas e o teor de proteínas nas folhas $(0,27)$ sugere que este nutriente exerce influência positiva sobre este parâmetro, concordando com os resultados observados por SUDO et al. (1982). 
Para carboidratos solúveis e a relação proteinas/carboidratos não foi observada correlação com o peso larval, supondo que o nivel mínimo destes compostos determinado entre os tratamentos seja suficiente para as exigências no ganho de peso das lagartas do bicho-da-seda.

Não existem registros na literatura brasileira sobre o peso da lagarta de $B$. mori em variedades de amoreira e em outros paises, os estudos são mais direcionados ao peso das pré-pupas.

\subsubsection{Peso das pré-pupas}

O peso das pré-pupas foi afetado pelos genótipos utilizados como alimento das lagartas. Os insetos criados no hibrido $1 Z-13 / 6$ apresentaram pré-pupas mais pesadas, sendo que o valor médio obtido neste material foi estatisticamente superior àqueles registrados em ' $I Z-40$ ' e 'IZ-64' e da variedade Korin. Não se registraram diferenças dos outros genótipos entre si ou com estes híbridos (Tabela 4).

De modo geral, as diferenças encontradas para peso das lagartas se repetiram no peso das pré-pupas, uma vez que a maioria dos híbridos que proporcionaram maior peso das lagartas se comportaram de forma semelhante na fase de pré-pupa. Apenas os hibridos $1 Z-40$ e $I Z-64$ nos quais os pesos das lagartas não diferiram dos melhores tratamentos, produziram pré-pupas menos pesadas. 
TAYADE \& JAWALE (1984) observaram pesos das pré-pupas que variaram de 3,62 a $4,05 \mathrm{~g}$ de acordo com a variedade de amoreira da qual as lagartas se alimentaram. SARATCHANDRA et al. (1992) registraram de 3,83 a $4,91 \mathrm{~g}$ de peso das pré-pupas. A maioria dos resultados de peso das pré-pupas deste trabalho situa-se no intervalo citado por este autor, embora ele tenha utilizado variedades de amoreira e raças de $B$. mori diferentes.

Não foi observada correlação entre os nutrientes das folhas e o peso das pré-pupas, entretanto a alta correlação entre o peso das pré-pupas e das glândulas sericígenas $(0,67)$ recomenda a utilização de variedades de amoreira que proporcionem maior desenvolvimento larval, ou seja, aqueles que, dentro dos limites observados, apresentem maiores quantidades de proteínas nas folhas.

\subsubsection{Peso das glândulas sericígenas}

O resultado obtido para o peso das glândulas sericígenas apresentou valores diferentes entre os tratamentos (Tabela 4). O peso obtido no híbrido $\mid Z-13 / 6$ foi semelhante nos híbridos $I Z-3 / 2,|Z-15 / 7| Z-,57 / 2$ e na variedade Korin e superior estatisticamente a todos aqueles que apresentaram peso das glândulas sericigenas menor que $1,78 \mathrm{~g}$.

Entre os tratamentos, houve uma tendência de que os melhores hibridos no peso das pré-pupas se destacaram no peso das glândulas. Os híbridos IZ-40 e IZ-64 que produziram pré-pupas de menor peso, também proporcionaram resultados semelhantes nos pesos das glândulas sericígenas. 
Tabela 4. Peso das lagartas, das pré-pupas e das glândulas sericigenas do bicho-da-seda ( $B$. mori), alimentado com folhas de híbridos e de uma variedade de amoreira. Gália-SP, 1994.

\begin{tabular}{cccc}
\hline & Peso das & Peso das & Peso das \\
Híbridos & lagartas & pré-pupas & glândulas \\
& $(\mathrm{g})$ & $(\mathrm{g})$ & sericígenas $(\mathrm{g})$
\end{tabular}

$\begin{array}{llll}\text { IZ-3/2 } & 5,53 \mathrm{ab} & 4,76 \mathrm{ab} & 1,95 \mathrm{ab} \\ \mathrm{IZ}-13 / 6 & 5,63 \mathrm{a} & 5,19 \mathrm{a} & 2,06 \mathrm{a} \\ \mathrm{IZ}-15 / 7 & 5,66 \mathrm{a} & 4,78 \mathrm{ab} & 1,90 \mathrm{abc} \\ \mathrm{IZ}-19 / 13 & 5,41 \mathrm{ab} & 4,73 \mathrm{ab} & 1,75 \mathrm{bc} \\ \mathrm{Z}-56 / 4 & 5,52 \mathrm{ab} & 4,65 \mathrm{ab} & 1,78 \mathrm{bc} \\ \mathrm{IZ}-57 / 2 & 5,45 \mathrm{ab} & 4,77 \mathrm{ab} & 1,87 \mathrm{abc} \\ \mathrm{IZ}-40 & 5,51 \mathrm{ab} & 4,45 \mathrm{~b} & 1,72 \mathrm{bc} \\ \mathrm{IZ}-64 & 5,52 \mathrm{ab} & 4,33 \mathrm{~b} & 1,68 \mathrm{c} \\ \text { Var. Korin } & 5,06 \mathrm{~b} & 4,57 \mathrm{~b} & 1,85 \mathrm{abc}\end{array}$

As médias seguidas de mesma letra não diferem entre si, pelo teste de Tukey, ao nivel de $5 \%$ de probabilidade. 


\subsection{Produção de casulos do bicho-da-seda em híbridos de amoreira}

\subsubsection{Peso do casulo}

Os resultados obtidos para o peso dos casulos (Tabela 5) mostram que existiram diferenças estatísticas e que o híbrido $\mid Z-64$ proporcionou menor peso médio do casulo. As lagartas alimentadas com folhas deste hibrido produziram casulos cujo peso não diferiu do ' $I Z-40$ ', sendo inferiores a todos os outros tratamentos. $\mathrm{O}$ híbrido ${ }^{\prime} \mathrm{IZ}-4 \mathrm{O}^{\prime}$ apresentou resultado semelhante àqueles dos genótipos IZ-3/2 e Korin, sendo inferiores aos demais.

Não foi verificada diferença significativa entre os tratamentos que produziram casulos com mais de 2,22 gramas.

Houve uma relação entre duração do quinto ínstar e peso do casulo. Aqueles genótipos nos quais as lagartas tiveram menor período do último instar (IZ-56/4, IZ-15/7 e Korin) produziram casulos mais pesados, evidenciando a melhor qualidade do alimento desse material.

Esta observação concorda com MACHII \& KATAGIRI (1991) que registraram entre variedades de amoreira que as lagartas com menor duração do último ínstar também produziram casulos mais pesados. Os autores verificaram pesos médios dos casulos entre 1,80 e $2,51 \mathrm{~g}$. Neste intervalo situam-se os valores de peso do casulo encontrados neste trabalho. 
O peso do casulo é um parâmetro importante na criação do bicho-da-seda, uma vez que representa um dos principais componentes da produção.

Assim, FONSECA et al. (1990) alimentaram lagartas de B. mori com os mesmos hibridos utilizados no presente estudo e com as variedades Calabresa e Catânia 1 como testemunhas. Verificaram que os híbridos IZ-3/2 e IZ$13 / 6$ proporcionaram casulos mais pesados. Os resultados de peso do casulo registrados pelos autores foram diferentes, já que o maior valor $(1,84 \mathrm{~g})$ foi inferior ao menor peso médio do casulo $(2,0 \mathrm{~g})$ obtido neste trabalho. As diferenças talvez possam ser explicadas pela utilização da variedade Calabresa nos dois primeiros instares de todos os tratamentos, além de que os resultados são médias de várias criações durante alguns anos em outra região do Estado (Limeira-SP). A idade das plantas não foi citada, sendo este um outro fator que pode ter influenciado os resultados.

\subsubsection{Peso da pupa}

Os pesos médios de pupas de $B$. mori observados nos diferentes híbridos de amoreira e na variedade Korin, encontram-se na Tabela 5. Os resultados diferiram estatisticamente, o que evidencia a influência dos genótipos que serviram como alimento das lagartas. 
Analogamente ao que foi discutido para o peso do casulo, o peso das pupas pode ser um reflexo da adequação alimentar dos genótipos de amoreira utilizados na fase larval.

A correlação negativa $(-0,26)$ entre a quantidade de carboidratos solúveis nas folhas dos genótipos de amoreira e o peso de pupa foi significativo, indicando que existe uma certa dependência entre eles e que o peso de pupa foi, de forma geral, maior naqueles materiais com menores niveis de carboidratos solúveis.

Não foi observada correlação com a proteina bruta, entretanto, existiu correlação significativa e positiva entre a relação proteina/carboidrato e o peso das pupas $(0,23)$, reforçando a hipótese de que maiores niveis de carboidratos e relativamente menos proteina podem influenciar negativamente 0 desempenho biológico do bicho-da-seda.

Esses resultados concordam com aqueles observados por LI \& SANG (1984) que registraram a maior duração da fase larval e menor peso do casulo quando lagartas de $B$. mori foram alimentadas com folhas de amoreira com alta quantidade de carboidratos e baixa de proteína.

\subsubsection{Peso da casca sérica}

Houve diferença significativa no peso médio da casca sérica de casulos de B. mori, demonstrando que este foi afetado pelos genótipos de 
amoreira testados (Tabela 5). Os valores médios variaram entre 0,46 e $0,52 \mathrm{~g}$, nos híbridos IZ-64 e 1Z-57/2, respectivamente.

O híbrido IZ-64 não diferiu estatisticamente da variedade Korin e do híbrido $\mathrm{Z}-40$ diferindo de todos os outros tratamentos, evidenciando a influência desse material na produção de seda de $B$. mori.

Tabela 5. Peso do casulo, da pupa e da casca sérica do bicho-da-seda ( $B$. mori) alimentado com folhas de híbridos e de uma variedade de amoreira. Gália-SP, 1994.

\begin{tabular}{lccl}
\hline Hibridos & $\begin{array}{c}\text { Peso do } \\
\text { casulo } \\
(\mathrm{g})\end{array}$ & $\begin{array}{c}\text { Peso da } \\
\text { pupa } \\
(\mathrm{g})\end{array}$ & $\begin{array}{c}\text { Peso da } \\
\text { casca } \\
\text { sérica }(\mathrm{g})\end{array}$ \\
\hline $\mathrm{Z}-3 / 2$ & $2,22 \mathrm{ab}$ & $1,75 \mathrm{ab}$ & $0,502 \mathrm{ab}$ \\
$\mathrm{IZ}-13 / 6$ & $2,28 \mathrm{a}$ & $1,76 \mathrm{a}$ & $0,518 \mathrm{a}$ \\
$\mathrm{IZ}-15 / 7$ & $2,28 \mathrm{a}$ & $1,76 \mathrm{a}$ & $0,510 \mathrm{ab}$ \\
$\mathrm{IZ}-19 / 13$ & $2,29 \mathrm{a}$ & $1,78 \mathrm{a}$ & $0,513 \mathrm{ab}$ \\
$\mathrm{IZ}-56 / 4$ & $2,30 \mathrm{a}$ & $1,78 \mathrm{a}$ & $0,517 \mathrm{a}$ \\
$\mathrm{IZ}-57 / 2$ & $2,26 \mathrm{a}$ & $1,74 \mathrm{ab}$ & $0,526 \mathrm{a}$ \\
$\mathrm{IZ}-40$ & $2,12 \mathrm{bc}$ & $1,64 \mathrm{~b}$ & $0,478 \mathrm{bc}$ \\
$\mathrm{IZ}-64$ & $2,00 \mathrm{c}$ & $1,53 \mathrm{c}$ & $0,464 \mathrm{c}$ \\
Var. Korin & $2,25 \mathrm{ab}$ & $1,75 \mathrm{a}$ & $0,492 \mathrm{abc}$ \\
& & & \\
\hline
\end{tabular}

As médias seguidas de mesma letra não diferem entre si, pelo teste de Tukey, ao nivel de $5 \%$ de probabilidade. 
Não foi observada correlação entre o teor de nutrientes das folhas dos genótipos de amoreira utilizados pelas lagartas e o peso da casca sérica.

As diferenças encontradas para o peso da casca sérica provaveimente podem se refletir em criações comerciais, onde este parâmetro tem influência direta na avaliação do teor de seda do casulo, através do qual é determinado o valor da produção.

Os dados registrados para este parâmetro são resultantes da influência dos genótipos de amoreira no desenvolvimento das lagartas, já que os hibridos IZ-64 e IZ-40 que apresentaram valores baixos nos parâmetros biológicos larvais, também apresentaram menor peso da casca sérica.

FONSECA et al. (1990) observaram pesos da casca sérica entre 0,36 e $0,42 \mathrm{~g}$ entre híbridos de amoreira e MACHII \& KATAGIRI (1991) registraram peso da casca sérica de $B$. mori no intervalo de 0,46 a $0,58 \mathrm{~g}$, no qual situam-se os resultados observados neste trabalho.

\subsubsection{Teor de seda}

O teor de seda é um parâmetro muito utilizado no meio sericícola para avaliação da qualidade do casulo, o qual representa a porcentagem de fio efetivamente extraido do casulo.

De acordo com os dados observados (Tabela 6), os valores de teor de seda apresentaram poucas variações, diferindo estatisticamente apenas entre os híbridos $1 Z-64$ e IZ-57/2 com relação à variedade Korin. 
Como se trata de um número relativo, o peso da pupa pode influenciar negativamente o parâmetro. Desta forma, para mesmo peso da casca sérica, o tratamento Korin que apresentou maior peso da pupa em relação ao 'IZ$64^{\prime}$ apresentou menor teor de seda.

Nos tratamentos com resultados estatisticamente semelhantes, o teor de seda variou de 17,15 a 17,77. Todavia, a diferença numérica entre eles é relativamente grande, de acordo com a avaliação da qualidade do casulo com base no teor de seda (Apêndice 1), que influencia o preço final da produção.

Os tratamentos apresentaram comportamentos diferentes e os valores foram superiores àqueles determinados por FONSECA et al. (1990) em casulos produzidos por lagartas alimentadas nestes híbridos de amoreira. Os autores registraram teor de seda de $16,89 \%$ nos casulos do híbrido $\mid Z-57 / 2$ e $17,50 \%$ no hibrido $\mathrm{IZ}-40$.

\subsubsection{Comprimento do fio}

O comprimento do fio dos casulos de B. mori interessa principalmente às indústrias de fiação de seda e pelos resultados observados, foi influenciado pelo alimento fornecido às lagartas.

Não foi observada correlação significativa entre a proteína e carboidratos solúveis das folhas dos genótipos de amoreira utilizado e 0 comprimento do fio de seda. 
Os resultados diferiram estatisticamente entre o hibrido IZ-3/2 e os genótipos IZ-40, IZ-19/13 e Korin, não havendo diferenças significativas nos demais tratamentos (Tabela 6).

A amplitude de 194,18 metros de fio entre os tratamentos extremos evidencia o efeito que os genótipos de amoreira exercem sobre o parâmetro estudado. Estes resultados suportam aqueles observados por QADER et al. (1992) que verificaram diferentes comprimentos do fio de seda de acordo com a variedade de amoreira na qual as lagartas de $B$. mori se desenvolveram.

Os valores médios registrados neste trabalho foram superiores àqueles encontrados na literatura que variaram de 625 a $900 \mathrm{~m}$ (THANDAMANI \& VIVEKANANDAN, 1984); de 665 a 1224m (PERIASAMY \& RADHAKRISHNAN, 1985). No Brasil, TOLEDO (1992) verificou 1099,7 metros de comprimento médio do fio entre raças de $B$. mori, cujas lagartas foram alimentadas com folhas da variedade Miura.

Como os parâmetros da produção refletem a qualidade do alimento fornecido às lagartas do bicho-da-seda, esses valores sugerem que a produção dos híbridos, mesmo diferindo entre si, é superior àquelas determinados em outras variedades de amoreira.

\subsubsection{Produção de casulos}

A produção média de casulos de $B$. mori foi significativamente influenciada pelos genótipos utilizados na alimentação das lagartas (Tabela 6). 
Este parâmetro dá a resposta quantitativa da produção de casulos, o qual inclui a porcentagem de encasulamento e o peso dos casulos de cada tratamento.

Tabela 6. Comprimento do fio, teor de seda, produção de casulos e valor da produção do bicho-da-seda (B. mori) alimentado com folhas de híbridos e de uma variedade de amoreira. Gália-SP, 1994.

\begin{tabular}{|c|c|c|c|c|}
\hline Híbridos & $\begin{array}{l}\text { Comprimento } \\
\text { do fio } \\
\text { (m) }\end{array}$ & $\begin{array}{c}\text { Teor de } \\
\text { seda } \\
(\%)\end{array}$ & $\begin{array}{l}\text { Produção } \\
\text { de casulos } \\
\text { (g) }\end{array}$ & $\begin{array}{c}\text { Valor da } \\
\text { produção } \\
(\mathrm{R} \$)\end{array}$ \\
\hline $\mid Z-3 / 2$ & 1436,06 a & $17,34 a b$ & $102,89 a$ & 1,94 \\
\hline $\mid Z-13 / 6$ & $1276,80 a b$ & $17,44 a b$ & $102,67 \mathrm{a}$ & 1,95 \\
\hline $\mid Z-15 / 7$ & $1304,93 a b$ & $17,18 \mathrm{ab}$ & $106,27 \mathrm{a}$ & 1,98 \\
\hline $\mid Z-19 / 13$ & $1258,94 b$ & $17,15 \mathrm{ab}$ & $100,65 a b$ & 1,88 \\
\hline $1 Z-56 / 4$ & $1297,18 a b$ & $17,26 a b$ & $105,53 a$ & 1,98 \\
\hline $\mid Z-57 / 2$ & $1361,46 a b$ & $17,71 \mathrm{a}$ & 103,69 a & 2,00 \\
\hline $1 Z-40$ & $1241,88 \quad b$ & $17,26 a b$ & $90,48 \quad b c$ & 1,69 \\
\hline $1 Z-64$ & $1277,89 a b$ & $17,77 \mathrm{a}$ & $87,82 \quad c$ & 1,69 \\
\hline Var. Korin & $1267,53 b$ & $16,81 \quad b$ & $101,49 a$ & 1,86 \\
\hline
\end{tabular}

As médias seguidas de mesma letra não diferem entre si, pelo teste de Tukey, ao nivel de $5 \%$ de probabilidade.

${ }^{1}$ Médias das oito repetições.

${ }^{2}$ Total das oito repetições. 
Os genótipos que proporcionaram mais de $100,0 \mathrm{~g}$ de casulos não diferiram entre si e apresentaram resultados superiores ao tratamento 'IZ-64', no qual se deu a menor produção de casulos.

O hibrido IZ-15/7 produziu 17,3 e $14,8 \%$ mais que os ' $Z$ - 64 ' e 'IZ-40' respectivamente, ressaltando o potencial daquele material para utilização na sericicultura.

Como a produção de casulos está diretamente ligada à quantidade e qualidade das folhas de amoreira, provavelmente o 'IZ-56/4' seja superior aos demais, já que se destaca como mais produtivo em quantidade de folhas (FONSECA \& FONSECA, 1986) e de casulos, neste trabalho.

\subsubsection{Valor da produção}

Este parâmetro pode ser utilizado em testes com o bicho-daseda já que leva em conta a qualidade da produção (porcentagem de desclassificados), peso dos casulos e teor de seda (Apêndice 1).

O valor da produção foi determinado a partir da quantidade de casulos produzidos e o teor de seda observados em cada tratamento, utilizando-se o valor zero de descontos, já que o número de casulos desclassificados foi menor que $1 \%$.

Os híbridos $1 Z-57 / 2,1 Z-15 / 7$ e $1 Z-56 / 4$ se destacaram dos demais no preço da produção de casulos. Para o 'IZ-40' e 'IZ-64' foi registrado o 
valor da produção $15,5 \%$ menor que aquele verificado no ' $I Z-57 / 2$ '. Os demais apresentaram valores intermediários (Tabela 6).

Estes valores são muito significantes quando se leva em conta uma criação comercial do bicho-da-seda, já que apenas no fator qualidade da folha, pode-se obter uma produção de casulos $18,3 \%$ maior entre os híbridos de amoreira testados. Isso somado a diferenças na producão foliar pode possibilitar um incremento considerável na produtividade da sericicultura brasileira. 


\section{CONCLUSÕES}

Os resultados obtidos neste trabalho, permitem concluir que:

- Não há influência dos híbridos testados na duração dos primeiro e terceiro ínstares de B. mori;

- Os híbridos de amoreira afetam a duração da fase larval, o peso das lagartas, das pré-pupas e das glândulas sericigenas;

- Existe correlação positiva entre o teor de proteina nas folhas dos híbridos testados e o peso das lagartas no máximo desenvolvimento;

- Os híbridos $1 Z-15 / 7$ e $1 Z-40$ proporcionam respectivamente, maior e menor porcentagem de encasulamento das lagartas de $B$. mori; 
- A produção, o teor de seda e o comprimento do fio dos casulos são influenciados pelos hibridos de amoreira;

- Os pesos do casulo e da casca sérica são menores nos híbridos IZ-40 e IZ-64 e o peso da pupa no IZ-64.

- Dos parâmetros estudados os mais adequados à comparação de genótipos de amoreira para a criação do bicho-da-seda são a produção e o teor de seda dos casulos;

- Os melhores híbridos para produção de casulos do bicho-daseda são IZ-57/2, IZ-56/4 e IZ-15/7. 


\section{REFERÊNCIAS BIBLIOGRÁFICAS}

AJAI-KOUL. Growth and silk production in silkworm (Bombyx mori L.) fed on four different varieties of mulberry. Research and Development Report, 3(2): 13-5, 1986. Apud Plant Breeding Abstracts, 1988, 058-05348.

ALMEIDA, J.E.; SOARES, A.R.; RAMALHO, M.A.P.; FONSECA, T.C. Phenotipal stability in the mulberry. Sericologia, 31(3): 475-8, 1991.

ARAI, N. \& ITO, T. Nutrition of the silk-worm, Bombyx mori. XVI Quantitative requirements for essential amino acids. Bull. Sericul. Exp. Sta., 21: 373-84, 1967.

CHAPMAN, R.F. The insects: structure and function. Cambridge, Massachussets, Harvard University Press, 1982.

CORREA, A.A.D. Bioquimica nos solos, nas pastagens e forragens. Paris, Caloustre Gulbekian, 1983. p.330. 789p.

DADD, R.H. Nutrition: organism. In: KERKUT, G.A. \& GILBERT, L.I., eds. Comprehensive insect physiology biochemistry and pharmacology. Oxford, Pergamon Press, 1985. v.8, p.319-90. 
DAS, B.C. \& SIKDAR, A.K. Evaluation of some improved strains of mulberry by feeding experiment. Indian J. Sericul., 9: 267-70, 1970.

DAS, P.K. \& VIJAYARAGHAVAN, K. Studies on the effect different mulberry varieties and seasons on the larval development and cocoon characters of silkworm Bombyx mori (L.). Indian J. Sericiculture, 29(1): 44-53, 1990.

FONSECA, A.S.; PAOLIERI, L.; FONSECA, T.C.; CAMPOS, B.E.S. Competição de variedades de amoreira. B. Indust. Anim., Nova Odessa, 33(2): 319-23, jul/dez. 1976.

FONSECA, T.C. \& VENCOVSKY, R. Estimação de parâmetros visando à seleção de hibridos artificiais de amoreira (Morus alba). B. Indust. Anim., Nova Odessa, 38(1): 85-105, jan/jun. 1981.

FONSECA, A.S.; FONSECA, T.C.; PAOLIERI, L. Híbridos naturais de amoreira. B. Indust. Anim., Nova Odessa, 42(1): 71-7, jan/jun. 1985a.

FONSECA, A.S.; FONSECA, T.C.; PAOLIERI, L. Melhoramento da amoreira por meio de hibridação artificial. B. Indust. Anim., Nova Odessa, 42(2): 265-76, jul/dez. 1985b.

FONSECA, A.S. \& FONSECA, T.C. Cultura da amoreira e criação do bicho-daseda. São Paulo, Nobel, 1986. 246p.

FONSECA, A.S.; FONSECA, T.C.; CHAMASS, E.A. Competição de hibridos naturais e artificiais de amoreira. B. Indust. Anim., Nova Odessa, 43(3): 367-73, jul/dez. 1986. 
FONSECA, A.S.; FONSECA, T.C.; CHAMASS, E.A. Competição de híbridos artificiais de amoreira. II. B. Indust. Anim., Nova Odessa, 44(2): 315-22, jul/dez. $1987 a$.

FONSECA, A.C.; FONSECA, T.C.; SCHAMASS, E.A. Competição de híbridos naturais e artificiais de amoreira. III. B. Indust. Anim., Nova Odessa, 44(2): 3238, jul/dez. 1987b.

FONSECA, A.S.; FONSECA, T.C.; CUNHA, E.A.; SCHAMASS, E.A. Competição de variedades, híbridos naturais e híbridos artificiais de amoreira. IV. B. Indust. Anim., Nova Odessa, 44(2): 329-34, jul/dez. 1987c.

FONSECA, T.C.; ALMEIDA, J.E. de; FONSECA, A.S. Effect of mulberry selection on silkworm feeding. Sericologia, Titabar, 30(4): 475-7, 1990.

FONSECA, T.C.; ALMEIDA, J.E.; OKAMOTO, F.; CUNHA, E.A. Valeur nutritif de quelques clones de murrier (Morus alba L.). Sericologia, Titabar, 33(4): 623-30, 1993.

GUPTA, B.K.; SINHA, A.K.; DAS, B.C. Improved technology for sericulture in West bengal. Indian Farming, 35(10): 20-1, 1986.

HAMANO, K. \& OKANO, T. Effects of dietary levels of protein an pyridoxine on growth of yonger larvae of the silkworm Bombyx mori. J. Seric. Sci. Jpn., 58(3): 203-8, 1989.

HAZAMA, K. Breeding of mulberry tree. Japan Agric. Res. Quart, 3(2): 15-9, 1968.

HIRANO, $H$. Varietal differences of leaf protein profiles in mulberry. Phytochemistry, 21(7): 1513-18, 1982. 
HORIE, Y.; INOKUCHI, T.; WATANABE, K. Effects of dietary amino acids balances on growth and cocoon quality in the silkworm, Bombyx mori. Bull. Sericul. Exp. Sta., 24: $345-65,1970$.

HORIE, Y. Quantitative requirement of nutrients for growth of the silkworm, Bombyx mori L. J.A.R.Q., 12(4): 211-17, 1978.

HORIE, Y. \& WATANABE, H. Recents advances in sericulture. Ann. Rev. Entomol., 25: 49-71, 1980.

HORIE, $Y . \&$ WATANABE, $K$. Effect of various kinds of dietary protein and suplementation with limiting amino acids on growth, haemolymph components and uric acid excretion in the silkworm, Bombyx mori. J. Insect. Physiol., 29(2): $187-99,1983$.

IDE, S. Efeito da composição mineral das folhas de amoreira sobre o crescimento do bicho-da-seda. Fertilité, Paris, 33: 3-18, fev/mar. 1969.

ITO, T. Nutritive values of carbohydrates for the silkworm, Bombyx mori. Nature, 187: $527,1960$.

ITO, T. \& ARAI, N. Nutrition of the silkworm, Bombyx mori. VIII. AMino acids requirements and nutritive effects of various proteins. Bull. Sericul. Exp. Sta., 19: 345-73, 1965.

JACQUES, A.V.A. Fisiologia do crescimento de plantas forrageiras. In: SIMPÓSIO SOBRE MANEJO DE PASTAGENS. Anais... Piracicaba, 1973. p.95-101.

JOHNSON, R.R.; BALWANI, T.L.; JOHNSON, L.J.; MCCLURE, K.E.; DEHORITY, B.A. Corn plant matutiry. J. Anim. Sci., 25:617-23, 1966. 
KASTURI BAI, A.R. Science and study of the silkworm. Sericologia, Titabar, 24(4): 455-71, 1984.

$L I, R$. \& SANG, O. The relationship between quality of mulberry leaves and some economics characters during the later larval stage. Science of Seric., 10(4): 197-201, 1984.

MACHII, K. \& KATAGIRI, K. Varietal differences in nutritive values of mulberry leaves for rearing silkworms. Japan Agric. Res. Quart, 25: 202-08, 1991.

MCNEILL, S. \& SOUTHWOOD, T.R.E. The role of nitrogen in the development of insect plant relationships. In: Biochemical aspects of plant and animal coevolution. Phytochemical Society of Europe. Annual Proceedings, 15, 1978. p.73-98.

MACRAE, J.C. \& ARMSTRONG, D.G. Enzyme method for determination of $\alpha$ linked glucose polymers in biological materials. J. Sci. Fd. Agric., 19: 578-581, 1968.

MURARI, O. Determinação das necessidades em proteina e energia do bicho-daseda (Bombyx mori L.) nos três instares finais da fase larval. Jaboticabal, FCAVIUNESP, Dissertação de mestrado, 1993. 63p.

NAGATA, M. \& KOBAYASHI, J. Effects of nutrition in storage protein concentration in the larval hemolyph of the silkworm, Bombyx mori. J. Seric. Sci. Jpn., 59(6): 469-74, 1990.

PANG-CHUAN, W. \& DA-CHUANG, C. Silkworm rearing. Agricultural Services Bulletin, FAO, Roma, 1988. 83p. 
PAOLIERI, L. \& FROTA, A. Competição de variedades de amoreiras. Boletim Técnico de Sericicultura, Campinas, 37: 16, 1970.

PARRA, J.R.P. Consumo e utilização de alimentos por insetos. In: PANIZZI, A.R. \& PARRA, J.R.P. Ecologia nutricional de insetos e suas implicações no manejo de pragas. Ed. Manole, São Paulo, 1991. p.9-66.

PARRA, J.R.P. \& CARVALHO, S.M. Biologia e nutrição quantitativa de Spodoptera frugiperda (Smith, 1797) em meios artificiais compostos de diferentes variedades de feijão. An. Soc. Entomol. Brasil., 13(2): 305-19, 1984.

PERIASMY, K. \& RADHAKRISHNAN, S. A quantitative study of food utilization and silk production in Bombyx mori L. for evaluation of superior varieties of mulberry. Sericologia, Titabar, 25(4): 491-500, 1985.

PILLAI, S.V. \& JOLLY, M.S. An evaluation on quality of mulberry varieties raised under hill conditions and the crop results of Bombyx mori (L.). Indian J. Sericiculture, 24(2): 48-52, 1985.

POORE, M.H.; ECK, T.P.; SWINGLE, R.S.; THEURER, C.B. Total starch and relative starch availability of feed gains. Abstr. 35, 20th Biennial Conference of Rumen Function, Chicago, 1989.

QADER, M.A. Nutritive value of mulberry leaves correlation. Sericologia, Titabar, 31(4): 419-24, 1991.

QADER, M.A.; HAGUE, R.; ABSAR, N. Nutritive effects of differents types of mulberry leaves on larval growth and cocoon characters of Bomby mori $L$. Pakistan J. Zool., 24(4): 341-345, 1992. Apud: Review Agric. Entomol., 81(8): 582, 1993. 
RÚBIA, A.C. Variedades de amoreira e seu emprego na criação do bicho-da-seda. Rev. Agricultura, Piracicaba, 39(2): 83-7, 1964.

RÚBIA, A.C. \& ABRAMIDES, E. Resultados preliminares de ensaio de variedades $x$ espaçamentos $x$ épocas de poda em amoreira no sistema cepo. Rev. Agricultura, Piracicaba, 40(2): 59-62, 1965.

RÚBIA, A.C.; PETTINELI, A.; ABRAMIDES, E. Produção de folhas de diferentes variedades de amoreiras durante o período de formação das mudas nos sistemas de cepo e fuste. Bragantia, Campinas, 25(17): 203-9, 1966a.

RÚBIA, A.C.; ALOISI SOBRINHO, J.; ABRAMIDES, E. Efeito da época de poda e do espaçamento sobre a produção de folhas de diferentes variedades, formadas no sistema de cepo. Bragantia, Campinas, 25(20): 233-6, $1966 \mathrm{~b}$.

SARATCHANDRA, B.; RAJANNA, L.; PHILOMENA, K.L.; PARAMESHA, C.; RAMESH, S.P.; JAYAPPA, T.; SABITHA, M.G. An evaluation of elitemulberry varieties for yield and quality through bioassay. Sericologia, Titabar, 32(1): 127 $34,1992$.

SAVOPOULOU-SOULTANI, M.; STRAURIDIS, D.G.; VASSILIOU, A.; STAFILIDS, J.E.; IRAKLIDIS, I. Response of Lobesia botrana (Lepidoptera: Tortricidae) to levels of sugar and protein in artificial diets. J. Econ. Entomol., Washington, 87(1): 84-90, 1994.

SCARPELLI, E.; BONILHA, N.A.; ABREU, O.C.; MALAVOLTA, E. Análise química da folha de amoreira Morus alba L. Boletim Técnico de Sericicultura, Campinas, 54: 11, 1969. 
SHARMA, B.; BADAN, F.; TARA, J.S. Comparative consumption, utilization, \% pupation and silk production in silkworms (Bombyx mori) fed on various varieties of mulberry exiting in Jammu Division of Jammu \& Kashmir State. Sericologia, Titabar, 26(4): 419-29, 1986

SHAW, G.G. Importance opf starches to spruce budworm (Lepidoptera: Tortricidae). Can. Ent, 150: 129-32, 1973.

SINGH, P. Artificial diets for insects, mites and spiders. Plenum Press, New York, 1977.

SLANSKY Jr., F. \& SCRIBER, J.M. Food consumption and utilization. In: KERKUT, G.A. \& GILBERT, L.J., eds. Comprehensive insect physiology, biochemistry and pharmacology. Oxford, pergamon press, 1985: v.3, p.87-163.

SUDO, M; SHO, Y.; OKAJIMA, T. The relation between the leaf quality at different leaf order and silkworm growth and cocoon quality. J. Serici. Sci. Japan, 50(4): 306-10, 1981.

TAKAHASHI, R.; KRONKA, S.N., KRONKA, R.N. Influência da variedade de amoreira na produção de casulos do bicho-da-seda na primavera, verão e outono. Zootecnia, Nova Odessa, 25(1): 77-84, jan/jun. 1987.

TAKAHASHI, R. \& KRONKA, R.S. Efeito dos diferentes tipos de adubação na produção de amoreira (Morus alba L.). B. Industr. anim., 46(1): 157-64, 1989.

TAKAHASHI, R.; LANDIM, C.D.; KRONKA, S.N. Desenvolvimento da glândula sericigena do bicho-da-seda (Bombyx mori L.) sob a influência dos diferentes tipos de adubação na amoreira. B. Industr. anim., 47(2): 121-5, 1990. 
TANAKA, Y. \& KUSANO, T. The haemolymph amylase activity during development of the silkworm Bombyx mori L. J. Sericult. Sci. Jpn., 49(2): 95-9, 1980.

TAYADE, D.S. \& JAWALE, M.D. Studies on the comparative performance of silkworm races against different varieties of mulberry under Marathwada conditions. Sericologia, Titabar, 24(3): 361-4, 1984.

THANGAMANI, R. \& VIVEKANANDAN, M. Physiological studies and leaf nutrient analysis in the evaluation of best mulberry variety. Sericologia, Titabar, 24(3): $317-24,1984$.

TINOCO, S.T.J.; OKAWA, H.; ALMEIDA, R.A.C. Levantamento da situação da sericicultura paulista. Doc. Téc. CATI, Campinas, nº 88, 1991.

TODOROKI, T. The present situation of sericulture in Japan. Sericologia, Titabar, 31(1): 43-5, 1991.

TOLEDO, J.O.A. Desempenho biológico e das caracteristicas tecnológicas do casulo de raças puras e híbridos do bicho-da-seda (Bombyx mori L.). Jaboticabal, FCAVIUNESP. Dissertação de mestrado, 1992. 99p.

VAADIA, Y.; RANEY, F.C.; HAGAN, R.M. Plant water deficits and physiological processes. Ann. Rev. Plant Physiol., 12: 265-92, 1961.

YAMASHITA, T. Changes in adenine nucleotides and development of ribulose biphosphate carboxylase activity during shooting of mulberry saplings. Plant and cell physiol., 24: 1151-5, 1983.

YAMASHITA, T. Mobilization of carbohydrates, amino acids and adenine nucleotides in hardwood stems during regrowth after partial shoot harvest in mulberry trees (Morus alba L.). Ann. of Botany, 52(2): 237-44, 1986. 
A P E N D ICE 
Apêndice 1. Tabela parcial de preços de casulos verdes (a partir de 01/07/94). Indústria de Seda BRATAC SIA.

Teor líquido

de seda $(\%)$
Preço $(R \$)^{*}$

por $\mathrm{kg}$

17,8

2,43

17,7

2,42

17,6

2,41

17,5

2,39

17,4

2,38

17,3

2,36

17,2

2,35

17,1

2,34

* US\$ comercial $=R \$ 0,89$ 